\title{
Spectrum of diseases in a medical ward of a teaching hospital in a developing country
}

\author{
B.R. Pokharel ${ }^{1}$, S. Humagain. ${ }^{2}$ P. Pant. ${ }^{3}$, R. Gurung ${ }^{4}$, R. Koju. ${ }^{5}$, T.R.S Bedi. ${ }^{6}$ \\ Department of Internal Medicine, Kathmandu University School of Medical Sciences, Dhulikhel, Kavre
}

\begin{abstract}
Communicable and respiratory tract diseases especially chronic obstructive pulmonary diseases are the main reasons of admission in medical ward of low and middle income countries. This is different from the developed countries where non communicable diseases are the main reasons of hospital admission. In developing countries the data of hospital admission are still lacking. Therefore this study will help us to assess the common patterns of diseases admitted in a medical ward, the average length of hospital stay etc. The record of 1040 hospitalized patients in medical ward was analyzed for the period of six months from Jan 2010 to Jun 2010. Patient's medical records were retrieved and data analysis was done to obtain age, sex, common diagnosis, the affected system and the duration of the hospital stay. The data was analyzed by using SPSSV 16. After reviewing the data the most common age of patients being admitted were between 46-65 years (31.5\%) followed by more than 65 years $(25 \%)$ between 26-45 years $(21.28 \%)$ and less than 25 years $(21.28 \%)$. Among the admitted patients females were more than the males except in neurolog ward. The most effected system was respiratory $(31.73 \%)$, and the most common diagnosis was Chronic obstructive pulmonary diseases $(23.17 \%)$. The next common system involved was gastroenterology including liver $(18.64 \%)$, genitourinary $(12.01 \%)$, cardiovascular ( $11.34 \%)$, neurology $(9.23 \%)$, endocrine $(4.80 \%)$ hematology $(2.30 \%)$. The cause for hospital admission by infection in different system was $(30.08 \%)$ The average duration of hospital stay of the patients was less than 7 days. The respiratory diseases and the infectious disease are the most common disease in Nepal. The communicable diseases still hold a greater position, while non communicable diseases are main reasons for admission to the medical wards in developed countries.
\end{abstract}

\section{Key words: Admissions, diagnosis, medical ward, patients.}

\section{Introduction}

It is believed that the pattern of medical diseases in developing countries is different than the developed countries. The decision to admit the patients in medical ward is determined by many factors like age, co existing

Correspondence: B.R. Pokharel

E-mail:drbrpokh@gmail.com illness, physical laboratory findings, the ability of oral intake of drugs and the resources available to the patients outside hospital ${ }^{1}$ Chronic diseases such as cardiovascular primarily heart disease, stroke, cancer and diabetes are the most common cause of health problem worldwide..$^{2-3}$ However the developing countries like ours are still struggling with the 
communicable diseases. Due to lack of awareness of sanitation, lack of good water supply and environment infectious diseases are still the major issues .Infectious diseases are a common cause of hospital admission in developing countries. ${ }^{4}$

In this setting the exact statics in our countries are lacking. Therefore the objectives of this study are to assess the patterns and prevalence's of diseases, the most common diagnosis and average duration of patient's hospital stay.

\section{Materials and methods}

A retrospective cross-sectional study was conducted from Jan 2010 -Jun 2010 on the patients who were admitted to the medical wards of Kathmandu University Hospital, Dhulikhel. The hospital serves about 4 districts which are east of Kathmandu valley with a very wide catchment area. It is training center for about 60 medical students each year along with other nursing and paramedical students. The hospital is 317 bedded with different specialties like internal medicine, surgery, gynecology and obstetrics, orthopedics, pediatrics, eye, ENT, dermatology. The number of bed allocated to internal medicine department is 75 along with 6 bed in Intensive care unit. The main diagnostic modalities in hospital are routine laboratories investigation, radiology including CT scan, microbiology and histopathology.

All patients admitted in medical ward during the study period as mentioned above were included and no sampling technique was used. The dependent variables in this study were reasons for admissions, the systems involved .The other variables were age, sex and duration of hospital stay. Data collections were done from the medical record department in a structured format sheet after taking permission from institutional review committee. Then the data were analyzed by using SPSS v16.

\section{Results}

A total of 1040 hospitalized medical ward patients during the period of six months were reviewed. The most common age group admitted in medical ward was between 46-65 yrs (31.53\%), followed by more than 65yrs (25\%), between 26-45yrs (21.28\%) and less than 25 yrs were $21.28 \%$ (Table 1 ).

Table 1: Distribution of hospitalized patient by age group

\begin{tabular}{lll}
\hline Age group & No of patients & Percent \\
\hline$<25$ yrs & 227 & $21.82 \%$ \\
$26-45$ yrs & 221 & $21.25 \%$ \\
$46-65$ yrs & 328 & $31.53 \%$ \\
$>65$ yrs & 264 & $25.38 \%$ \\
\hline Total & 1040 & 100 \\
\hline
\end{tabular}

The most common affected system was respiratory system $31.73 \%$ followed by gastrointestinal including liver $18.64 \%$, cardiovascular $11.34 \%$, genitourinary $12.01 \%$, neurology $9.23 \%$, endocrine $4.80 \%$ (Table 2 ).

Table 2: Distribution of hospitalized patients by affected system.

\begin{tabular}{lcc}
\hline System & No & Percent \\
\hline Cardiovascular & 118 & 11.34 \\
Respiratory & 330 & 31.73 \\
Hematology & 24 & 2.3 \\
Endocrine & 50 & 4.8 \\
Hepatobiliary & 42 & 4.03 \\
Neurology & 96 & 9.23 \\
Gastrointestine & 152 & 14.61 \\
Renal & 125 & 12.01 \\
Rheumatology & 1 & 0.09 \\
Others & 102 & 9.8 \\
\hline Total & 1040 & 100 \\
\hline
\end{tabular}


B.R. Pokharel et al. Spectrum of diseases in a medical ward.

Chronic obstructive pulmonary diseases is the commonest disease requiring admission $(23.17 \%)$ followed by Urinary tract Infection, Pneumonias, Poisoning, Enteric fever, acute gastro enteritis, hypertension etc (Table 3).

Table 3: Most common diseases

\begin{tabular}{lll}
\hline Disease & No & Percentercent \\
\hline COPD & 241 & 23.17 \\
UTI & 101 & 9.71 \\
Pneumonia & 61 & 5.86 \\
Poisoining & 59 & 5.67 \\
Enteric fever & 59 & 5.67 \\
AGE & 56 & 5.38 \\
HTN & 55 & 5.28 \\
DM & 47 & 4.51 \\
Tuberculosis & 36 & 3.47 \\
Ischemic Heart Disease & 25 & 2.4 \\
\hline Total & 740 & \\
\hline
\end{tabular}

Infection accounted for the most admissions (30.08\%) which included enteric fever, tuberculosis, pneumonia, viral fever, chicken pox, mumps and acute gastroenteritis. Most systems showed higher frequency of female admission except neurology in which male predominates. In cardiovascular diseases, there were equal admissions (Fig. 1).

The average hospital stay of patients was 4.69 days and $85.28 \%$ of the patients stayed for less than 7 days. The longest stay in hospital was for uncontrolled diabetes for which the patient stayed for 39 days.
Fig. 1: Distribution of hospitalized patient by affected system and sex

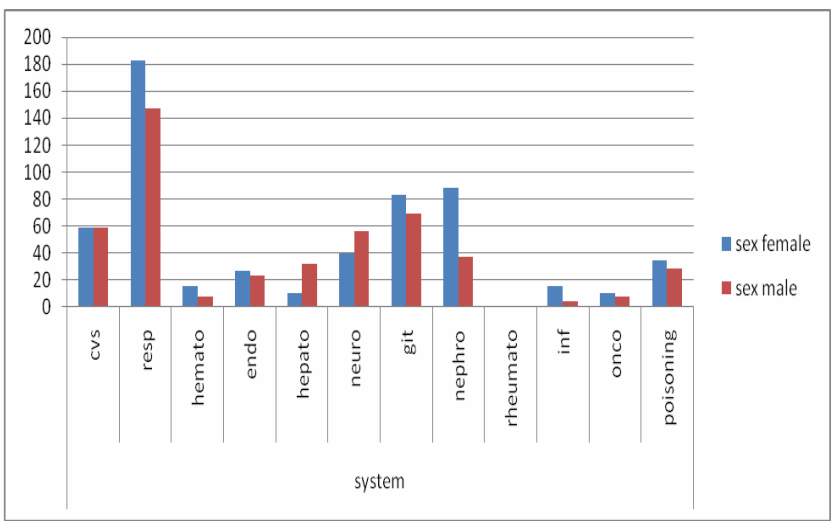

Table 4: Length of Hospital Stay

\begin{tabular}{lllll}
\hline System & $\begin{array}{l}\mathbf{0 - 7} \\
\text { days }\end{array}$ & $\begin{array}{c}\mathbf{8 - 1 4} \\
\text { days }\end{array}$ & $\begin{array}{c}\mathbf{1 5 - 3 0} \\
\text { days }\end{array}$ & $\begin{array}{c}\mathbf{>} \mathbf{3 0} \\
\text { days }\end{array}$ \\
\hline Cardiovascular & 100 & 16 & 2 & 0 \\
Respiratory & 276 & 45 & 7 & 2 \\
Hematology & 21 & 1 & 2 & 0 \\
Endocrine & 35 & 9 & 4 & 2 \\
Hepatobiliary & 30 & 12 & 0 & 0 \\
Neurology & 83 & 10 & 1 & 2 \\
Gastrointestine & 140 & 11 & 1 & 0 \\
Renal & 110 & 14 & 1 & 0 \\
Rheumatology & 1 & 0 & 0 & 0 \\
\hline Others & 91 & 6 & 4 & 1 \\
\hline
\end{tabular}

\section{Discussion}

It was observed that respiratory tract diseases and infectious diseases were major reasons for medical ward admissions at Kathmandu university hospital. Elderly patients required most admissions (46 to 65 years followed by $>65$ Years). These findings is contrast with 
Journal of College of Medical Sciences-Nepal, 2012, Vol-8, No-2

findings of Elias A et al which shows the mean age of admission between 21 to 30years. ${ }^{5}$ These findings are also similar with the South African and Nigerian studies which showed that the patient admitted were above 40 years. ${ }^{6-7}$

The most common affected system was respiratory system $31.73 \%$. This is probably due to increased amount of tobacco use and air pollution. In particular, smoking is very common in underdeveloped countries. The annual cigarette consumption has increased in the developing world, tobacco consumption continues to rise at $3.4 \%$ in $2002 .{ }^{8}$ The reason was aggressive marketing by tobacco companies; delay in implementing antismoking regulations and because of the public perception of risk of smoking is still low. ${ }^{9}$ Infectious diseases accounts for $30.8 \%$ of all admission mainly UTI, Pneumonias, enteric fever, Acute gastroenteritis and tuberculosis. These findings are similar with Hussian KP which shows communicable diseases pneumonia 36\% and parasites $16 \% .{ }^{10}$ This may be due to poor socio economic condition, poor hygiene and poor sanitation. However these findings contradicts with findings of Australia. In the Australian study, the most common reason for hospital admission to the medical ward was cardiovascular diseases $29 \% .{ }^{11}$ In another study, admission to medical ward in Hong Kong were most frequently associated with cardiovascular system which made up $30.3 \%$ of all medical cases. ${ }^{12}$ These differences in the diseases pattern between these countries may be due to high income, better quality of food, high immunization, better sanitation and living standard.
The average hospital stay of patient in medical ward was less than seven days. These finding are similar with finding of Omer S. which also clearly shows the average hospital stay were less than seven days. ${ }^{13}$

\section{Conclusions}

Nepal is still a developing country where a health care facility to all populations especially in remote areas is limited. The socio-economic status and many human disease are as comparable with African countries. COPD is the most common cause of admission followed by infective diseases such as UTI, pneumonia enteric fever, tuberculosis etc. These common diseases can be prevented by taking anti smoking measures by improving indoor pollution and awareness of people.

\section{References}

1. L.A. Mandell, R. Wunderlink. Community Acquired Pneumonia: Treatment ,site of care in L.D. Kasper, E. Braunwald, A.S. Fauci, L.S. Hauser, Longo L.D. Jamesson J.L,editors Harrisons principles of internal medicines $17^{\text {th }}$ ed. New York: McGraw-Hill2008Pp.1622- 23.

2. P. Kardas, E. Ratajczyk-Pakalska. Reasons for elderly patient's hospitalization in department of internal medicine in Lodz. Aging Clin Exp Res. 2003 :15(1); 25 31.

3. Respiratory Diseases in Canada. Canadian institute for health information. canidian lung association. Health Canada. Statics Canada. Ottawa .Canada. September 2001:1-102.

4. World Health Organization. WHO Report on Tuberculosis Epidemics, 1997.Geneva:WHO1997?

5. A. Elias. Reasons and outcome of admissions, Ethiop $J$ Health Sci. 2010;21(2):113-20.

6. J. Marszalek, P.J. De Villiers, Morbidity Profile Of admission to Gf Jooste Hospital,Manenberg ,cape Town, SA Fam Pract .2006;48(6):15-15e. 
B.R. Pokharel et al. Spectrum of diseases in a medical ward.

7. S.B. Garko, N. Ekweanic, C.A. Anyiam. Duration of Hospital stay and Mortality in medical wards of Ahmadu Bello university Teaching Hospital, Kaduna; Nigeria, Annals Of African Medicines. 2003;2(2):68-71.

8. WHO/WPRO- smoking statics, world health organization regional office for western pacific 2002-0508; http// www.wpro.who.int/media centre /fact sheet / fs 20020258

9. A.S. Abdullah, C.G. Hustein, Promotion of smoking cessation in developing countries; a frame work for urgent public health intervention. Thorax. 2004;59: 623-30.
10. K. Hussein. Pattern of Medical admission to Jimma Hospital. Bull. Inst. Health Sci. 1997;7(1):51-62.

11. E.G. Saint Medical morbidity in a general hospital. Med J Aust.1960;2: 601-8.

12. J.C. Pan, T.D. Cheung, Chau Y.N. Hospital .medical and cardio vascular diseases, admission in Hong Kong Hospital. Bulletin Hong Kong Medical association. 1982;34: 55-62.

13. O.S. Alamoudi et.al. Pattern of diseases in Hospitalized patients. JKAU Med Sci.2009;16 (4): 3-11. 